\title{
The interaction of $\alpha$-chlorohydrin with glycerol kinase
}

\author{
D. E. Brooks \\ Department of Animal Physiology, University of Adelaide, Waite Agricultural Research \\ Institute, Glen Osmond, South Australia 5064
}

\begin{abstract}
Summary. $\alpha$-Chlorohydrin has been examined both for its ability to act as a substrate for glycerol kinase and as an inhibitor of the reaction of glycerol with glycerol kinase. Using a purified enzyme from Candida mycoderma, it was established that $\alpha$-chlorohydrin does not act as a substrate for glycerol kinase, but does act as a competitive inhibitor $\left(K_{1}\right.$ of $\left.30 \mathrm{~mm}\right)$ of purified glycerol kinase and the enzyme present in a sonicated preparation of ram spermatozoa. Neither $\alpha$ chlorohydrin nor $\alpha$-chlorohydrin phosphate acted as inhibitors of NAD- or flavinlinked glycerolphosphate dehydrogenase. It is concluded that $\alpha$-chlorohydrin does not cause the impairment of sperm metabolism as a result of phosphorylation catalysed by glycerol kinase.
\end{abstract}

\section{Introduction}

$\alpha$-Chlorohydrin causes reversible sterility in male rats and several other species (see Coppola, 1969; Ericsson \& Baker, 1970; Krieder \& Dutt, 1970; Johnson \& Pursel, 1972) apparently by affecting the metabolic capabilities of spermatozoa in the cauda epididymidis. Sufficient evidence has now accumulated to suggest that $\alpha$-chlorohydrin is not itself the active compound causing disruption of sperm metabolism. For instance, a period of preincubation of ram spermatozoa with $0 \cdot 1-1 \mathrm{~mm}-\alpha$-chlorohydrin is required before an inhibition of glycerol metabolism is noted (Edwards, Dacheux \& Waites, 1976). Furthermore, the activity of a number of glycolytic enzymes is substantially reduced when measured in ram spermatozoa which have been incubated with $0.03-300 \mathrm{mM}-\alpha$-chlorohydrin before extraction, yet these same enzymes are not inhibited by the direct addition of $\alpha$-chlorohydrin to extracts of unincubated spermatozoa (Mohri, Suter, Brown-Woodman, White \& Ridley, 1975; Brown-Woodman, Mohri, Mohri, Suter \& White, 1978). A number of acrosomal enzymes is also inhibited after, but not before, incubation with 50-120 mm- $\alpha$-chlorohydrin (Yang \& Srivastava, 1976).

Due to the structural similarity of $\alpha$-chlorohydrin to glycerol, it seemed possible that $\alpha$-chlorohydrin might enter the metabolic machinery of spermatozoa by a phosphorylation step catalysed by glycerol kinase. In fact, synthetic $\alpha$-chlorohydrin phosphate has been shown to be an inhibitor of both sperm glyceraldehyde phosphate dehydrogenase and triose phosphate isomerase (Mohri et al., 1975; Mashford \& Jones, 1978). Moreover, high concentrations of glycerol can overcome the inhibitory effect of $\alpha$-chlorohydrin on ram spermatozoa (Edwards $e t$ al., 1976; Brown-Woodman et al., 1978), suggesting competition between the two compounds for the same pathway. Such competition is supported by the report that $\alpha$-chlorohydrin is a competitive inhibitor of glycerol kinase prepared from Escherichia coli (Thorner, 1972; see Brooks, Hamilton \& Mallek, 1974).

The present work was carried out to examine in more detail the possibility that $\alpha$ chlorohydrin acts as a substrate for glycerol kinase and to determine the kinetics of the interaction of $\alpha$-chlorohydrin with this enzyme. 


\section{Materials and Methods}

$\alpha$-Chlorohydrin (D,L-1,chloro-2,3-propanediol) designated as $99 \%$ pure was obtained from Aldrich Chemical Co., Inc., Milwaukee, Wisconsin, U.S.A. This preparation was further purified by distillation at $1 \mathrm{mmHg}$ pressure $\left(85^{\circ} \mathrm{C}\right.$ distillation temperature $)$ and separate fractions were collected. Before use, $\alpha$-chlorohydrin phosphate (D,L-1,deoxy-1,chloro-3,phosphoglycerol; prepared by reacting epichlorohydrin with phosphoric acid) was diluted in water and carefully neutralized with $\mathrm{NH}_{4} \mathrm{OH}$ with rapid stirring to avoid local contact with high $\mathrm{pH}$. Glycerol kinase (EC 2.7.1.30; $80 \mathrm{U} / \mathrm{mg}$ from Candida mycoderma) and glycerolphosphate dehydrogenase (EC 1.1.1.8; $60 \mathrm{U} / \mathrm{mg}$ ) were purchased from Boehringer Mannheim Australia Pty Ltd, Melbourne, Australia. Ram semen was collected by electrical stimulation (Blackshaw, 1954) and the spermatozoa were separated from seminal plasma by the procedure of Harrison (1976). The pellet of spermatozoa was frozen and subsequently thawed and sonicated for a total of $1 \mathrm{~min}$ in

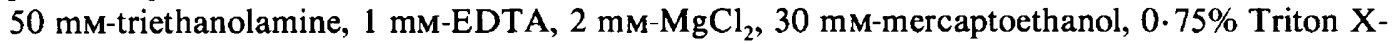
100 , pH 7.5. The pellet of sonicated spermatozoa, recovered after centrifugation at $600 \mathrm{~g}$ for 10 min, was resuspended in fresh medium and used as the source of sperm glycerol kinase as no activity was liberated in a soluble form by this procedure.

Glycerol kinase was assayed in $1 \mathrm{ml}$ volume at $25^{\circ} \mathrm{C}$ using a double-beam recording spectrophotometer (SP-1800 from Pye-Unicam, Cambridge, U.K.). The reaction mixture contained 180 mM-glycine, $3.8 \mathrm{M}$-hydrazine hydrate, $2 \mathrm{~mm}-\mathrm{MgCl}_{2}, 1.4 \mathrm{~mm}-\mathrm{ATP}, 1 \mathrm{~mm}-\mathrm{NAD}^{+}$, $1 \mathrm{~mm}-\mathrm{KCN}, 1.2 \mathrm{U}$ glycerolphosphate dehydrogenase $/ \mathrm{ml}$ adjusted to $\mathrm{pH} 9.8$ with $5 \mathrm{M}-\mathrm{HCl}$. Various amounts of glycerol or $\alpha$-chlorohydrin were added, and an equivalent volume of water was added to the blanks. The reaction was initiated by the addition of glycerol kinase to all cuvettes. Glycerol was estimated by the same procedure, except that an excess $(1.5 \mathrm{U} / \mathrm{ml})$ of glycerol kinase was added. NAD-linked glycerolphosphate dehydrogenase (EC 1.1.1.8) was assayed in the forward direction in a medium containing $180 \mathrm{mM}$-glycine, $3.8 \mathrm{M}$-hydrazine hydrate, 1 mM-NAD ${ }^{+}, \mathrm{pH} 9.8$, and the reaction was initiated by adding various concentrations of D,L-glycerol 3-phosphate. Flavin-linked glycerolphosphate dehydrogenase (EC 1.1.99.5) was assayed as described by Brooks (1978).

$a$-Chlorohydrin and glycerol were separated by (a) descending chromatography on Whatman No. 1 paper using ethylacetate:pyridine:water (10:4:3, by vol.) and (b) thin-layer chromatography on plates coated with silica gel and developed with chloroform:methanol (7:3, $\mathrm{v} / \mathrm{v})$. The $R_{F}$ values for $\alpha$-chlorohydrin and glycerol were respectively 0.86 and 0.54 in system (a) and 0.78 and 0.43 in system (b). Spots were located on paper chromatograms with the $\mathrm{AgNO}_{3}$ reagent of Trevelyan, Proctor \& Harrison (1950) and on thin-layer plates by spraying with $1 \% \mathrm{KMnO}_{4}$ containing $1 \% \mathrm{NaOH}$ (Pacsu, Mora \& Kent, 1949) or with potassium periodocuprate (Bonner, 1960). Phosphorylated compounds were separated by electrophoresis $(2500 \mathrm{~V}$ for $1 \mathrm{~h}$ ) on Whatman $3 \mathrm{MM}$ paper in $1 \mathrm{M}$-acetic acid, $0.7 \mathrm{M}$-formic acid, $\mathrm{pH} 1.7$ (Efron, 1968). Phosphorus-containing compounds were located with the dipping reagent of Harrap (1960).

Glycerylphosphorylcholine (GPC) was obtained as the $\mathrm{CdCl}_{2}$ complex from Sigma Chemical Co., St. Louis, Missouri, U.S.A. GPC was freed from $\mathrm{CdCl}_{2}$ by passing $5 \mathrm{ml}$ of a 50 mM solution through a column containing $4 \mathrm{ml}$ Dowex $50 \mathrm{WX} 8\left(\mathrm{H}^{+}\right.$form) layered over $4 \mathrm{ml}$ of Dowex AG1X2 (acetate form) and washing through with $50 \mathrm{ml}$ water. The effluent was dried and made up in $250 \mu \mathrm{l}$ water. The concentration of GPC was determined by phosphate analysis after incineration (Brooks, 1970).

Chloride was determined by titration against $\mathrm{Ag}$ in $4 \mathrm{ml} 1.7 \mathrm{M}$-acetic acid, 0.1 M-nitric acid containing $0.25 \mathrm{mg}$ gelatin/ml in a chloridometer (Laboratory Glass Instrument Corp., New York, U.S.A.). 


\section{Results}

$\alpha$-Chlorohydrin as a substrate for glycerol kinase

Preliminary results revealed that a reaction occurred when undistilled $\alpha$-chlorohydrin was added as the substrate in the spectrophotometric assay for glycerol kinase, suggesting that $\alpha$ chlorohydrin was phosphorylated by glycerol kinase and that the phosphorylated product was oxidized by the coupling enzyme, glycerolphosphate dehydrogenase (Brooks, 1979). It was possible, however, that a minor impurity in the $\alpha$-chlorohydrin could have been responsible for the observed reaction, rather than $\alpha$-chlorohydrin itself. Chromatography of the $\alpha$-chlorohydrin did reveal glycerol as a contaminant which was quantitated by spectrophotometric assay $(0.8 \%$ contamination on a molar basis). An attempt was made to remove the glycerol by distillation. This was carried out at reduced pressure to avoid the decomposition of $\alpha$-chlorohydrin which occurs during distillation at atmospheric pressure (as stated by the manufacturer). Even the first fraction ( $7 \%$ of the total volume) contained some glycerol $(0.06 \%)$, later fractions contained more. When $50 \mathrm{~mm}$ of the first fraction from the distillation was retested in the spectrophotometric assay for glycerol kinase, very little reaction was evident.

As $\alpha$-chlorohydrin is unstable in alkali, forming glycidol with the accompanying release of chloride, the stability of $a$-chlorohydrin was tested in the hydrazine buffer used for the spectrophotometric assays. The rate of decomposition in this buffer $\left(\mathrm{pH} 9.8\right.$ and $25^{\circ} \mathrm{C}$ ) was only $2 \% / \mathrm{h}$. This was in contrast to its complete breakdown in about $1 \mathrm{~min}$ in $1 \mathrm{M}-\mathrm{NaOH}$ or when $\mathrm{NaOH}$ was added to the hydrazine buffer to a final concentration of $1 \mathrm{M}$.

It was still possible, however, that $\alpha$-chlorohydrin might be phosphorylated by glycerol kinase but that $\alpha$-chlorohydrin phosphate might not be a substrate for the coupling enzyme and hence no reaction would be recorded in the spectrophotometer. Indeed, $10 \mathrm{~mm}-\alpha$-chlorohydrin phosphate produced no reaction in the assay for $\mathrm{NAD}^{+}$-linked glycerolphosphate dehydrogenase. That $\alpha$-chlorohydrin phosphate did not inhibit this enzyme was checked by demonstrating that the rate of reaction with $10 \mathrm{mM}$-D,L-glycerol 3-phosphate as substrate was the same in the presence or absence of $10 \mathrm{~mm}-\alpha$-chlorohydrin phosphate. A similar absence of reaction was found when $30 \mathrm{~mm}$ - $\alpha$-chlorohydrin phosphate was tested in the assay for flavinlinked glycerolphosphate dehydrogenase using an homogenate of rat testis as the source of the enzyme.

In order to resolve definitely whether $\alpha$-chlorohydrin is phosphorylated by glycerol kinase, the products of the reaction with purified glycerol kinase were separated by paper electrophoresis. The reaction mixture contained $100 \mathrm{mM}^{-4}$-(2-hydroxyethyl)-1-piperazineethanesulphonic acid, $2 \mathrm{mM}-\mathrm{MgCl}_{2}, 17.5 \mathrm{mM}-\mathrm{ATP}, 5 \mathrm{U}$ glycerol kinase/ml, $\mathrm{pH} 7 \cdot 0$, and no substrate, $50 \mathrm{~mm}$-glycerol or $50 \mathrm{~mm}$ - $\alpha$-chlorohydrin. The mixture was allowed to react overnight at room temperature and $4 \mu \mathrm{l}$ aliquots were electrophoresed together with standards of glycerol 3-phosphate, $\alpha$-chlorohydrin phosphate, inorganic phosphate, ATP and ADP. There was clearly a formation of glycerolphosphate coupled with a complete conversion of ATP to ADP when glycerol was the substrate (Text-fig. 1). However, with $\alpha$-chlorohydrin as substrate there was no difference from the pattern observed in the control incubation without substrate (i.e. no formation of $\alpha$-chlorohydrin phosphate and no conversion of ATP to ADP).

\section{$\alpha$-Chlorohydrin as an inhibitor of glycerol kinase}

Using $50 \mathrm{~mm}$ of the redistilled preparation of $\alpha$-chlorohydrin (containing $0.03 \mathrm{~mm}$-glycerol), the kinetics of the effect of $\alpha$-chlorohydrin on the phosphorylation of glycerol were evaluated. $\alpha$-Chlorohydrin caused a reduction in the reaction rate in a competitive fashion (Text-fig. 2) with both the purified enzyme from Candida mycoderma and the sonicate of ram spermatozoa. Although the apparent $K_{\mathrm{m}}$ for glycerol differed in the two cases $(0.12 \mathrm{~mm}$ for the purified 


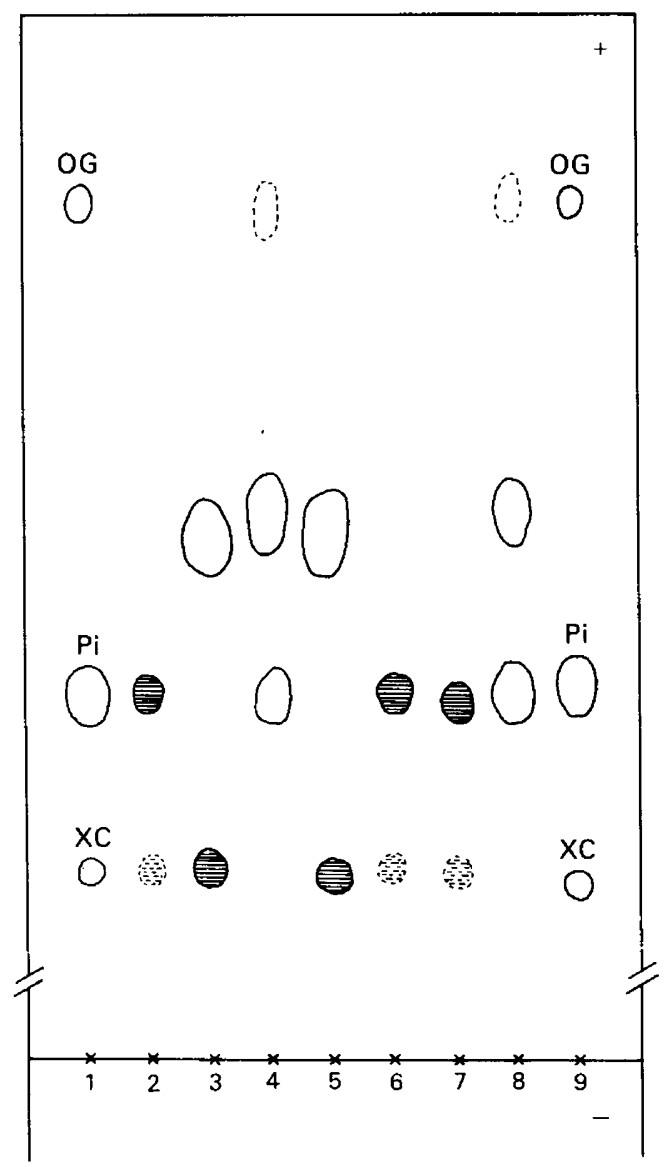

Text-fig. 1. Electrophoretogram of the reaction products formed by incubating glycerol or $\alpha$ chlorohydrin with glycerol kinase. The components of the reaction mixture, the conditions of electrophoresis and the procedures for locating spots on the electrophoretogram are described in 'Materials and Methods'. Spots absorbing u.v. light were located before dipping for phosphorus compounds and are designated by shading. Weakly absorbing or weakly staining spots are indicated by dotted outlines. Standard compounds were spotted as follows: lanes 1 and 9, inorganic phosphate (P) and two dyes, orange $G(O G)$ and xylenecyanol FF (XC); lane 2, ATP showing ADP as a minor contaminant; lane 3, ADP and D,L-glycerol 3-phosphate; lanes 4 and 8 , a-chlorohydrin phosphate showing inorganic phosphate and an unknown compound migrating in the position of $O G$ as contaminants. Aliquots of the reaction mixture for glycerol kinase were spotted as follows: lane 5 , glycerol as substrate; lane $6, \alpha$-chlorohydrin as substrate; lane 7, no substrate. The migration distance of $O G$ and $X C$ was 27 and $11 \mathrm{~cm}$ respectively.

enzyme and $0.04 \mathrm{~mm}$ for ram spermatozoa) the $K_{\mathrm{i}}$ for $\alpha$-chlorohydrin was the same (30 mM). Because glycerylphosphorylcholine (GPC) occurs in high concentration in the epididymal plasma (Brooks et al., 1974) and is structurally similar to $\alpha$-chlorohydrin, this compound was also tested as an inhibitor of glycerol kinase. GPC did cause competitive inhibition of the purified enzyme and the inhibitor constant ( $54 \mathrm{~mm}$ ) was of a similar magnitude to that of $\alpha$-chlorohydrin (30 mM).

That the inhibition in the spectrophotometric assay was due to an interaction of $\alpha$ chlorohydrin with glycerol kinase rather than with the coupling enzyme, glycerolphosphate dehydrogenase, as has been suggested by Brown-Woodman et al. (1978), was checked by adding different amounts of the latter enzyme. This resulted in no change in reaction rate, 

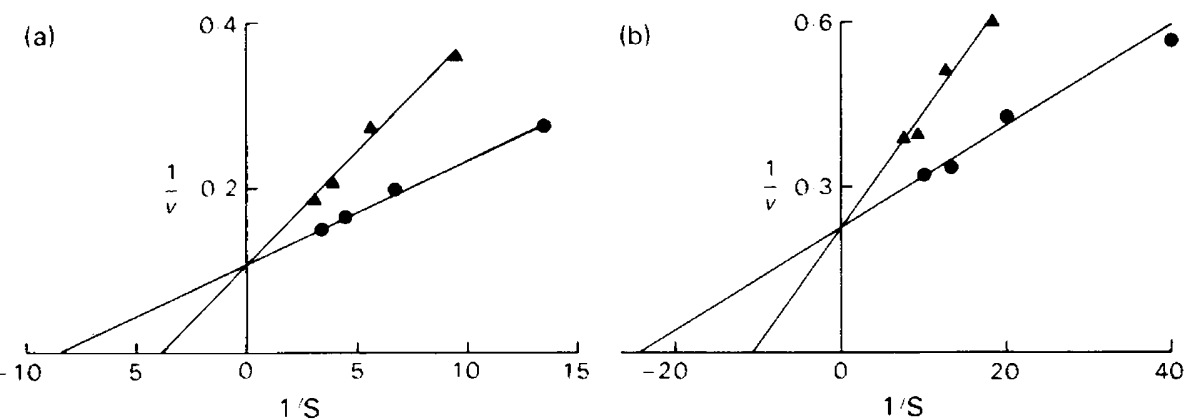

Text-fig. 2. Kinetic characteristics of the interaction of glycerol and $\alpha$-chlorohydrin with glycerol kinase. (a) Purified glycerol kinase (0.01 unit from Candida mycoderma); (b) sonicated ram spermatozoa $\left(2 \times 10^{7}\right.$ spermatozoa containing 0.004 unit glycerol kinase). 0 , Glycerol alone; $\Delta$, glycerol $+50 \mathrm{~mm}-\alpha$-chlorohydrin. The data are presented as double reciprocal plots to demonstrate the competitive nature of the interaction between glycerol and $50 \mathrm{~mm}-\alpha$ chlorohydrin, although kinetic constants were obtained directly from hyperbolic plots by the procedure of Wilkinson (1961). In determining the concentration of glycerol in the reaction mixture, account was taken of the contribution from the small contamination of glycerol in the $a$-chlorohydrin. The reaction velocity is expressed as $\mathrm{nmol} / \mathrm{min}$ and the substrate concentration as $\mathrm{mM}$. The apparent $K_{\mathrm{m}}$ for glycerol was $0.12 \mathrm{mM}$ for the purified enzyme and $0.04 \mathrm{mM}$ for sonicated ram spermatozoa, whereas the $K_{\mathrm{f}}$ for $\alpha$-chlorohydrin was $30 \mathrm{~mm}$ for both tests.

confirming that the coupling enzyme was present in excess and not limiting the rate of reaction. Moreover, when 0.06 units of the coupling enzyme in the assay for NAD-linked glycerolphosphate dehydrogenase, measured in the direction of glycerol phosphate oxidation, were used no inhibition of the rate of reaction with 1 or $10 \mathrm{mM}-\mathrm{D}, \mathrm{L}$-glycerol 3-phosphate was noted in the presence of $50 \mathrm{mM}-\alpha$-chlorohydrin.

$\alpha$-Chlorohydrin was also tested as an inhibitor of the flavin-linked glycerolphosphate dehydrogenase present in an homogenate of rat testis. No inhibition was observed with $20 \mathrm{~mm}-\alpha$ chlorohydrin when 2 or $5 \mathrm{mM}$-D,L-glycerol 3-phosphate were added as substrate. It was therefore apparent that neither the cytoplasmic nor mitochondrial forms of glycerolphosphate dehydrogenase are inhibited by $\alpha$-chlorohydrin at the concentrations tested.

The degree of inhibition of glycerol kinase by $\alpha$-chlorohydrin $\left(K_{\mathrm{i}}\right.$ of $\left.30 \mathrm{~mm}\right)$ is considerably less than that noted previously (Brooks, 1979). In the previous study, $\alpha$-chlorohydrin was included in both the test and blank cuvettes. Automatic subtraction of the reaction occurring in the blank cuvettes due to the presence of glycerol as a contaminant therefore resulted in an underestimate of the rate of reaction in the test cuvettes. In the present study $\alpha$-chlorohydrin was omitted from the blank cuvettes.

\section{Discussion}

These results have demonstrated that $\alpha$-chlorohydrin is not a substrate for purified glycerol kinase but does act as a competitive inhibitor of this enzyme. It must, therefore, be concluded that $\alpha$ chlorohydrin is unlikely to inhibit the metabolic activity of spermatozoa by conversion to $\alpha$ chlorohydrin phosphate, although the latter compound is a potent inhibitor of some sperm enzymes (Mohri et al., 1975; Mashford \& Jones, 1978).

Spermatozoa are well known to have the ability to oxidize glycerol (Mann \& White, 1957; White, 1957) via the activity of glycerol kinase (Mohri \& Masaki, 1967) and flavin-linked glycerolphosphate dehydrogenase (Mohri, Mohri \& Ernster, 1965; Schenkman, Richert \& Westerfeld, 1965; Brooks, 1978). The importance of the competitive inhibition of glycerol kinase 
by $\alpha$-chlorohydrin would be questionable, however, because the $K_{\mathrm{m}}$ for glycerol is low, so that the enzyme is saturated at relatively low concentrations of glycerol, while high concentrations of $\alpha$-chlorohydrin are needed to cause any marked inhibition. Although radioactivity accumulates in the lumen of the epididymis when $\left[{ }^{14} \mathrm{C}\right] \alpha$-chlorohydrin is administered to rats (Crabo \& Appelgren, 1972; Edwards, Jones \& Waites, 1975), it is highly likely that the accumulated material is not unchanged $\alpha$-chlorohydrin, but a dechlorinated product (Edwards et al., 1975; A. R. Jones, personal communication), and so spermatozoa in the cauda epididymidis may not be exposed to high concentrations of $\alpha$-chlorohydrin.

The demonstration that the antifertility effect of $\alpha$-chlorohydrin is specific to the $\mathbf{S}(+)$ isomer (Jackson \& Robinson, 1976; Ford, Harrison \& Waites, 1977; Jackson, Rooney \& Fitzpatrick, 1977) is comparable with the differential antifertility action of the isomers of 1,amino-3,chloro-2propanol (Paul, Williams \& Cohen, 1974; Coppola \& Saldarini, 1974) and might be construed to indicate an interaction of these compounds with a stereo-specific enzyme system. That glycerolphosphate dehydrogenase is not the stereo-specific enzyme in question is clear from the lack of effect of both $\alpha$-chlorohydrin and $\alpha$-chlorohydrin phosphate on either the NAD- or flavin-linked form of this enzyme.

This work was supported by a grant from the Australian Research Grants Committee. I am grateful to Dr M. E. Tate, Department of Agricultural Biochemistry, University of Adelaide, for distilling $\alpha$-chlorohydrin and running electrophoretograms; to Dr A. R. Jones, Department of Biochemistry, University of Sydney, for providing $a$-chlorohydrin phosphate; and to both for valuable discussion.

\section{References}

Blackshaw, A.W. (1954) A bipolar rectal electrode for the electrical production of ejaculation in sheep. Aust. vet.J. 30, 249-250.

Bonner, T.G. (1960) Detection of polyhydroxycompounds and their carboxylate esters with potassium periodatocuprate. Chemy Ind. p. 345.

Brooks, D.E. (1970) Acid-soluble phosphorus compounds in mammalian semen. Biochem. J. 118, 851857.

Brooks, D.E. (1978) Activity and androgenic control of enzymes associated with the tricarboxylic acid cycle, lipid oxidation and mitochondrial shuttles in the epididymis and epididymal spermatozoa of the rat. Biochem.J. 174, 741-752.

Brooks, D.E. (1979) Biochemical environment of sperm maturation. In The Spermatozoon, in press. Eds D. W. Fawcett \& J. M. Bedford. Urban \& Schwarzenburg, Baltimore.

Brooks, D.E., Hamilton, D.W. \& Mallek, A.H. (1974) Carnitine and glycerylphosphorylcholine in the reproductive tract of the male rat. $J$. Reprod. Fert. 36, 141-160.

Brown-Woodman, P.D.C., Mohri, H., Mohri, T., Suter, D. \& White, I.G. (1978) Mode of action of achlorohydrin as a male anti-fertility agent. Inhibition of the metabolism of ram spermatozoa by $\alpha$ chlorohydrin and location of block in glycolysis. Biochem. J. 170, 23-37.

Coppola, J.A. (1969) An extragonadal male antifertility agent. Life Sci. 8, 43-48.

Coppola, J.A. \& Saldarini, R.J. (1974) A new orally active male antifertility agent. Contraception $9,459-$ 470.

Crabo, B. \& Appelgren, L.-E. (1972) Distribution of $\left[{ }^{14} \mathrm{C}\right]$-chlorohydrin in mice and rats. $J$. Reprod. Fert. 30, 161-163.

Edwards, E.M., Jones, A.R. \& Waites, G.M.H. (1975) The entry of $\alpha$-chlorohydrin into body fluids of male rats and its effect upon the incorporation of glycerol into lipids. J. Reprod. Fert. 43, 225-232.

Edwards, E.M., Dacheux, J.-L. \& Waites, G.M.H. (1976) Effects of $\alpha$-chlorohydrin on the metabolism of testicular and epididymal spermatozoa of rams. $J$. Reprod. Fert. 48, 265-270.

Efron, M.L. (1968) High voltage paper electrophoresis. In Chromatographic and Electrophoretic Techniques, 2nd edn, Vol. II, pp. 166-193. Ed. I. Smith. Heinemann, London.

Ericsson, R.J. \& Baker, V.F. (1970) Male antifertility compounds: biological properites of $\mathrm{U}-5897$ and $\mathrm{U}$ 15,646. J. Reprod. Fert. 21, 267-273.

Ford, W.C.L., Harrison, A. \& Waites, G.M.H. (1977) Effects of the optical isomers of $\alpha$-chlorohydrin on glycolysis by ram testicular spermatozoa and the fertility of male rats. J. Reprod. Fert. 51, 105109.

Harrap, F.E.G. (1960) The detection of phosphate esters on paper chromatograms. Analyst, Lond. 85, 452 .

Harrison, R.A.P. (1976) A highly efficient method for washing mammalian spermatozoa. J. Reprod. Fert. 48, 347-353.

Jackson, H. \& Robinson, B. (1976) The antifertility effect of $\alpha$-chlorohydrins and their stereo-isomers in male rats. Chemico-Biol. Interactions 13, 193-197.

Jackson, H., Rooney, F.R. \& Fitzpatrick, R.W. (1977) Characterization and antifertility activity in rats of $\mathrm{S}(+) \alpha$-chlorohydrin. Chemico-Biol. Interactions 17, $117-120$. 
Johnson, L.A. \& Pursel, V.G. (1972) Reversible infertility in male swine fed $\alpha$-chlorohydrin. J. Anim. Sci. 34, 241-245.

Kreider, J.L. \& Dutt, R.H. (1970) Induction of temporary infertility in rams with an orally administered chlorohydrin. J. Anim. Sci. 31, 95-98.

Mann, T. \& White, I.G. (1957) Glycerol metabolism by spermatozoa. Biochem. J. 65, 634-639.

Mashford, P.M. \& Jones, A.R. (1978) The antifertility action of $\alpha$-chlorohydrin:enzyme inhibition by $\alpha$ chlorohydrin phosphate. Experientia 34, 1267-1268.

Mohri, H. \& Masaki, J. (1967) Glycerokinase and its possible role in glycerol metabolism of bull spermatozoa. J. Reprod. Fert. 14, 179-194.

Mohri, H., Mohri, T. \& Ernster, L. (1965) Isolation and enzymic properties of the midpiece of bull spermatozoa. Expl. Cell Res. 38, 217-246.

Mohri, H., Suter, D.A.I., Brown-Woodman, P.D.C., White, I.G. \& Ridley, D.D. (1975) Identification of the biochemical lesion produced by a-chlorohydrin in spermatozoa. Nature, Lond. 255, 75-77.

Pacsu, E., Mora, T.P. \& Kent, P.W. (1949) General method for paper chromatographic analysis of reducing and nonreducing carbohydrates and derivatives. Science, N.Y. 110, 446-447.

Paul, R., Williams, R.P. \& Cohen, E. (1974) Structureactivity studies with chlorohydrins as orally active male antifertility agents. Contraception 9, 451457.

Schenkman, J.B., Richert, D.A. \& Westerfeld, W. (1965) $\alpha$-Glycerophosphate dehydrogenase activity in rat spermatozoa. Endocrinology 76, 1055-1061.

Thorner, J.W. (1972) The molecular properties of glycerol kinase from Escherichia coli. Ph.D. thesis, Harvard University.

Trevelyan, W.E., Proctor, D.P. \& Harrison, J.S. (1950) Detection of sugars on paper chromatograms. Nature, Lond. 166, 444-445.

White, I.G. (1957) Metabolism of glycerol and similar compounds by bull spermatozoa. Am. J. Physiol. 189, 307-310.

Wilkinson, G.N. (1961) Statistical estimations in enzyme kinetics. Biochem. J. 80, 324-332.

Yang, C.H. Srivastava, P.N. (1976) Inhibition of bull and rabbit sperm enzymes by $\alpha$-chlorohydrin. $J$. Reprod. Fert. 46, 289-293.

Received 21 November 1978 